\title{
Formação inicial de professores na perspectiva inclusiva: levantamento de produções
}

\author{
Patrícia Aparecida Monico \\ Universidade Federal de São Carlos - São Carlos - SP - Brasil \\ Liz Amaral Saraiva Morgado \\ Universidade Federal de São Carlos - São Carlos - SP - Brasil \\ Rosimeire Maria Orlando \\ Universidade Federal de São Carlos - São Carlos - SP - Brasil
}

\begin{abstract}
Resumo
O presente estudo tem por objetivo sistematizar e analisar o levantamento de produções acadêmicas no período de 2008 a 2015 , especificamente no que se refere à formação inicial de professores na perspectiva inclusiva. Trata-se de revisão sistemática de literatura. A pesquisa foi realizada nos ambientes virtuais de duas bases de dados de acesso púbico: Portal de Teses e Dissertações da Coordenação de Aperfeiçoamento Pessoal de Nível Superior e a Biblioteca Nacional de Teses e Dissertações. Os resultados apontaram a construção de três categorias: (1) Distribuição dos trabalhos acadêmicos por período e titulação; (2) Local de produção; (3) Tema das produções acadêmicas. Os dados aqui apresentados indicam um número pequeno de produções cientificas, realizadas principalmente em Programas de Pós-Graduação em Educação, nos anos de 2009, 2011 e 2013. Se debruçam sobre a análise dos conteúdos curriculares das licenciaturas e o conhecimento dos alunos no que diz respeito à disciplina de Libras.
\end{abstract}

Palavras-chave: Educação especial; formação de professores; revisão sistemática.

\section{Initial teacher training in an inclusive perspective: production surveys}

\begin{abstract}
The present study aims to systematize and analyze the survey of academic productions in the period from 2008 to 2015 , specifically regarding initial teacher education in an inclusive perspective. This is a systematic review of the literature. The research was carried out in the virtual environments of two public access databases: Portal of Theses and Dissertations of the Coordination of Personal Improvement of Higher Level and the National Library of Theses and Dissertations. The results pointed to the construction of three categories: (1) Distribution of academic papers by period and degree; (2) Place of production; (3) Theme of academic productions. The data presented here indicate a small number of scientific productions, carried out mainly in Graduate Programs in Education, in the years 2009, 2011 and 2013. They focus on the analysis of the curricular contents of the degrees and the knowledge of the students in what it says respect to the discipline of Libras.
\end{abstract}

Keywords: Special education; teacher training; systematic review.

\section{Formación inicial de profesores en la perspectiva inclusiva: recogida de producciones}

\section{Resumen}

En el presente estudio se tiene por objetivo sistematizar y analizar la recopilación de producciones académicas en el período de 2008 a 2015 , específicamente en lo que se refiere a la formación inicial de profesores en la perspectiva inclusiva. Se trata de revisión sistemática de literatura. Se realizó la investigación en los ambientes virtuales de dos bases de datos de acceso púbico: Portal de Tesis y Tesinas de la Coordinación de Perfeccionamiento Personal de Nivel Superior y la Biblioteca Nacional de Tesis y Tesinas. Los resultados apuntaron la construcción de tres categorías: (1) Distribución de los estudios académicos por período y titulación; (2) Local de producción; (3) Tema de las producciones académicas. Los datos aquí presentados indican un número bajo de producciones científicas, realizadas principalmente en Programas de PostGrado en Educación, en los años de 2009, 2011 y 2013. Se abordan sobre el análisis de los contenidos curriculares de las licenciaturas y el conocimiento de los alumnos en lo que dice respeto a la asignatura de Libras.

Palabras clave: Educación especial; formación de profesores; revisión sistemática de literatura. 


\section{Introdução}

O presente artigo integra um projeto de pesquisa em rede intitulado "Acessibilidade no Ensino Superior: da análise das políticas públicas educacionais ao desenvolvimento de mídias instrumentais sobre deficiência e inclusão", financiado pelo Programa Observatório da Educação (EDITAL/CAPES N - 49/2012). Tem como foco a formação inicial de professores, na perspectiva inclusiva nas diferentes licenciaturas.

Tem por objetivo sistematizar e analisar o levantamento de produções acadêmicas no período de 2008 a 2015, especificamente no que se refere a formação inicial de professores na perspectiva inclusiva. Justifica-se a escolha de tal período pela presença de dois marcos importantes em tal temática, quais sejam, em 2008 a Política Nacional da Educação Especial na Perspectiva Inclusiva e em 2015 as Diretrizes Curriculares Nacionais para a formação inicial em nível superior e para a formação continuada.

O Brasil vivencia, desde o final do século passado e início do século XXI, tempos de amplo destaque no que diz respeito à luta pelos direitos sociais das pessoas com deficiência. Acompanhando o cenário internacional, no contexto Pós II Guerra Mundial, a Declaração Universal dos Direitos Humanos (ONU, 1948) deflagrou um processo de internacionalização dos direitos humanos. Para Bem (2006), os movimentos sociais são verdadeiros indicadores para a análise do funcionamento da sociedade, pois traduzem o permanente movimento das forças sociais e nos permitem identificar as tensões entre os diferentes grupos de interesses, expondo os mecanismos de luta da sociedade.

Gohn (1995) salienta que, no âmbito brasileiro, o século $X X$ pode ser encarado como o século em que os movimentos sociais efervesceram como fenômenos sociais abrangentes, um período de convergência de forças sociais em torno de lutas comuns e fundamentais para a construção da cidadania sociopolítica do país. Como destacam Orlando e Caiado (2014), desde o início do século XX, a história do Brasil é marcada pelo enfrentamento e lutas sociais, a exemplo da Greve Geral de 1917, considerada uma das mais importantes manifestações políticas da época; ou mais a frente, o período populista (1945-1968), que abriu oportunidade para o avanço de várias formas de participação social, como a disputa político partidária, a revitalização sindical ou movimentos por reforma de base da educação, que tiveram como conclusão a revolta estudantil de 1968 (Bem, 2006; Gohn, 1995).

Tais dados permitem que, no final do século $X X$ e início do século $\mathrm{XXI}$, impulsionados tanto pelo cenário internacional quanto nacional, deslumbremos certo avanço na organização de alguns movimentos sociais que lutam pela garantia dos direitos humanos das pessoas com deficiência, dando destaque à ampla participação de cidadãos, fato que traz diferentes repercussões na forma de conceber e tratar a deficiência, com desdobramentos, inclusive, na formação dos professores.

Atualmente a relevância dos estudos que buscam conhecer e analisar a formação inicial de professores na perspectiva da Educação Inclusiva pauta-se em compromisso assumido pela sociedade brasileira ao preconizar a educação como um direito de todos e a importância de se garantir acesso e permanência do público alvo da Educação Especial, preferencialmente no ensino comum. Entende-se por público alvo da Educação Especial pessoas com deficiência, transtornos globais do desenvolvimento e altas habilidades ou superdotação (Brasil, 1988, 2008; Lei n 12.796, 2013; Lei $n^{\circ}$. 13.146, 2015).

A presença destas pessoas no ensino comum se guia pelo princípio da educação inclusiva, conforme explicitado na Política Nacional de Educação Especial na Perspectiva da Educação Inclusiva. O movimento mundial pela educação inclusiva é uma ação política, cultural, social e pedagógica, desencadeada em defesa do direito de todos os estudantes de estarem juntos, aprendendo e participando, sem nenhum tipo de discriminação. A educação inclusiva constitui um paradigma educacional fundamentado na concepção de direitos humanos, que conjuga igualdade e diferença como valores indissociáveis, e que avança em relação à ideia de equidade formal ao contextualizar as circunstâncias históricas da produção da exclusão dentro e fora da escola (Brasil, 2008, p.1).

Vemos a educação caminhar para a tentativa de se alcançar uma escola que responda aos desafios de atender, com qualidade, uma diversidade de alunos que responda às proposições de uma educação na perspectiva inclusiva. A partir daí vários desafios são postos, pois desencadeia-se a necessidade de mudanças na estrutura e funcionamento da escola, entre eles, um em especial nos chama a atenção, a formação inicial de professores.

Durante os anos 80,90 do século $X X$ e início do século XXI, o Brasil apresentou alguns avanços na tentativa de se universalizar o ensino, quer seja na melhora do fluxo de matrículas, na expansão da Educação Infantil e do Ensino Médio (Mello, 2000), quer na inclusão de alunos da Educação Especial nas redes regulares de ensino, apontando para importantes desafios e uma ressignificação da formação inicial dos professores.

Segundo Leone e Leite (2011), a formação inicial para professores deve oferecer ao futuro professor uma base sólida de conhecimentos que the possibilite reelaborar continuamente os saberes iniciais, a partir do confronto com as experiências vividas no cotidiano escolar. Ou seja, conceber a etapa de formação inicial como a base para a aprendizagem contínua do professor.

Assim, perante este cenário que se impõe, é imprescindível focalizar a formação dos professores como objeto de estudo, que leve em conta sua relação com a sociedade, que considere as contradições, os conflitos e as tensões presentes.

Nesta direção, a exigência de novos conhecimentos e o desenvolvimento de novas práticas, diferente do que vinha se desenvolvendo, coloca em xeque o modelo de formação docente homogeneizadora, até então vigente.

Ao se pensar no acesso e permanência, por exemplo, da pessoa com deficiência no ensino comum brasileiro, há que se destacar que o aumento de matrículas destes alu- 
nos na escola regular tem demonstrado tanto uma conquista histórica de luta contra a exclusão como um desafio ao sistema escolar como um todo, e em especial aqui, à formação inicial de professores. A política inclusiva torna-se mais um enfrentamento para a escola brasileira, tanto pública quanto particular, já que a formação inicial de professores tem se apresentado com sérias lacunas, desde antes da garantia de acesso deste público ao ensino comum.

Atualmente, a Legislação Brasileira (Brasil, 2008; Lei $n^{\circ}$ 12.796,2013; Lei $n^{\circ}$. 13.146, 2015) e internacional (UNESCO, 1994) indicam a importância do público alvo da Educação Especial estar matriculado no ensino comum, e mais, que ofereça um currículo satisfatório que atenda toda necessidade de educação e garanta aprendizagens significativas. Problematizando, podemos questionar: $\mathrm{O}$ que consideram aprendizagens significativas? Que currículo se propõe? Que formação se dá ao professor?

Diante do quadro que se põe, a Proposta Diretrizes para Formação Inicial de Professores da Educação Básica em cursos de nível superior, documento nacional, indica que as mudanças propostas para a Educação Básica brasileira trazem enormes desafios à formação de professores e, embora destaque que a Educação Básica deva ser inclusiva, anuncia a desarticulação neste nível, entre o que se propõe estudar nos cursos de formação e os conteúdos que o professor vai ensinar em sala de aula (Brasil, 2000).

No contexto inclusivo, tecem-se expectativas em relação ao trabalho docente e a política corrobora com isso. Para que aconteça a apropriação devida dos conteúdos escolares do público alvo da Educação Especial, espera-se que o professor desenvolva práticas pedagógicas que consigam incluir todos os alunos. Para além disso, que também planeje suas aulas e que os alunos realizem atividades e se apropriem do conhecimento por meio de um processo educacional que favoreça a inclusão de todos, independentemente das especificidades.

A Proposta de Diretrizes para Formação Inicial de Professores da Educação Básica em cursos de nível superior indica a importância de uma provável revisão do processo de formação inicial de professores que, necessariamente, terá que enfrentar problemas no campo institucional, tais como segmentação da formação dos professores e descontinuidade na formação dos alunos da Educação Básica, submissão da proposta pedagógica à organização institucional, distanciamento entre os cursos de formação e o exercício da profissão de professor no Ensino Fundamental e Médio, entre outros; e no campo curricular, desconsideração do repertório de conhecimento dos professores em formação, tratamento inadequado dos conteúdos, desconsideração das especificidades próprias dos níveis e/ou modalidades de ensino em que são atendidos os alunos da Educação Básica etc. (Brasil, 2000).

Nesse cenário, as questões a serem enfrentadas na formação inicial são históricas, e o professor é elemento crucial, já que se torna peça importante neste percurso, enquanto mediador no processo educacional que visa, por meio de sua ação pedagógica, transformar a prática social (Saviani, 2005).

Diante dessa realidade, as produções acadêmicas podem nos dar pistas, para entendermos o quadro que se põe: O que apontam as produções acadêmicas sobre formação inicial de professores na perspectiva inclusiva? Os cursos de formação estão atentos a esta nova demanda? Que ações estão sendo desenvolvidas para esta formação?

\section{Procedimentos Metodológicos}

Para responder ao objetivo proposto, este estudo foi desenvolvido com base em uma revisão sistemática de literatura, apoiada na abordagem qualiquantitativa das produções encontradas.

A revisão sistemática diz respeito a um levantamento de estudos já publicados a partir de determinado tema, com o objetivo de buscar respostas a determinadas questões. É um método que permite maximizar o potencial de uma busca e deve se constituir em um trabalho reflexivo, crítico e compreensivo a respeito dos materiais analisados (Hohendorff, 2014; Costa \& Zoltowski, 2014).

Segundo Gatti (2004) a abordagem qualiquantitativa, sem tradição sólida no Brasil, nos revela um dado preocupante, pois existem problemas educacionais que para a realização de sua contextualização e compreensão, precisam ser trabalhados via dados quantitativos, como exemplo, a discussão sobre a formação inicial de professores e a educação inclusiva, aqui enfatizados, em que os números das produções acadêmicas localizadas e suas relações se tornam importantes para a compreensão do quadro que se configura. Considera-se que os métodos de análise de dados que se traduzem por números podem ser úteis na compreensão dos problemas educacionais e a combinação com dados vindos de metodologia qualitativa pode enriquecer esta análise.

As pesquisas científicas, enquanto produção de conhecimento, têm importante função social e política de auxiliar, a exemplo desta temática, na formação de professores e contribuir com sua prática pedagógica, além de indicar as tendências e demandas dos temas pesquisados. Assim, considerando os programas de pós-graduação importantes espaços para o desenvolvimento de pesquisas, é necessária a realização frequente de avaliações a respeito do que vem sendo desenvolvido, em termos de pesquisa científica, nas diversas áreas do conhecimento (Silva \& Gamboa, 2011). Deste modo, o levantamento de produções acadêmicas torna-se importante por apresentar o panorama e as tendências das pesquisas e o uso social destas.

Costa e Zoltowski (2014) indicam em um trabalho de revisão sistemática de qualidade oito etapas básicas que serviram como guia neste estudo: delimitação da questão a ser pesquisada; escolha das fontes de dados; eleição das palavras-chave (descritores) para a busca; busca e armazenamento dos resultados; seleção do material de acordo 
com critérios de inclusão e exclusão; extração dos dados; avaliação do material; síntese e interpretação dos dados.

A pesquisa foi realizada nos ambientes virtuais de duas bases de dados de acesso púbico: Portal de Teses e Dissertações da Coordenação de Aperfeiçoamento Pessoal de Nível Superior (CAPES) e a Biblioteca Nacional de Teses e Dissertações (BDTD). Utilizaram-se os seguintes descritores: Acessibilidade e Ensino Superior (1091 títulos); Acessibilidade e Formação de Professores (1060 títulos); Acessibilidade e Licenciatura (593 títulos); Acessibilidade e Educação Especial (1452 títulos) e Ensino Superior e Formação Inicial (1392 títulos), num total de 5588 títulos.

Como critérios de inclusão foram considerados os trabalhos nacionais e em língua portuguesa; referentes à temática formação inicial de professores na perspectiva da educação inclusiva; os que disponibilizaram pelo menos o resumo online; que atenderam ao período de 2008 a 2015. Cabe esclarecer que tal período foi escolhido pela presença de dois marcos importantes na temática, quais sejam, em 2008 a Política Nacional da Educação Especial na Perspectiva Inclusiva e em 2015 as Diretrizes Curriculares Nacionais para a formação inicial em nível superior e para a formação continuada. Os critérios de exclusão foram: duplicidade dos trabalhos; os que estivessem indisponíveis; e os que não tratassem do tema. $A$ partir daí, realizou-se a leitura dos títulos e dos resumos e o armazenamento dos resultados em planilhas.

No total foram encontradas quatro produções acadêmicas e agrupadas em três categorias: (1) Distribuição dos trabalhos acadêmicos por período e titulação; (2) Local de produção; (3) Temática das produções acadêmicas. A análise dos trabalhos acadêmicos possibilitou identificar, sistematizar e analisar um total de quatro produções científicas no período em foco, apresentados a seguir.

\section{Resultados e Discussões}

Conforme mencionado, de acordo com levantamento realizado no Banco de Teses e Dissertações da CAPES e na Biblioteca Nacional de Teses e Dissertações (BDTD), no período de 2008 a 2015, o foco foi refletir sobre três pontos importantes, quais sejam: o quando se realizaram as pesquisas, onde e do que tratam. Assim, sistematizaram-se os dados em três categorias: (1) Distribuição dos trabalhos acadêmicos por período e titulação: ano de publicação e nível de mestrado ou doutorado; (2) Local de produção: distribuição anual dos trabalhos acadêmicos por Instituições de Ensino Superior, Estado e Programas de Pós-Graduação; (3) Temática das produções acadêmicas: tema central das pesquisas.

No total foram encontradas quatro produções acadêmicas, conforme indicado na Tabela 1.

Da busca realizada no período de 2008 a 2015, localizaram-se três dissertações de mestrado e uma tese de doutorado. O primeiro trabalho data de 2009 e é o único de doutoramento localizado. Nos anos de 2010, 2012, 2014 e 2015, não foram localizados nenhum trabalho, apresentando, de acordo com o levantamento realizado, um vácuo
Tabela 1. Distribuição dos trabalhos acadêmicos por período e titulação.

\begin{tabular}{ccc}
\hline Ano & Mestrado & Doutorado \\
2009 & - & 1 \\
2011 & 2 & - \\
2013 & 1 & - \\
\hline Total & 3 & 1 \\
\hline
\end{tabular}

Fonte: Dados da pesquisa.

neste período. Há uma concentração de dois trabalhos de mestrado no ano de 2011, sendo a maior concentração no período. Bueno (2010), alerta para a diferença de tempo de titulação, ou seja, mestrado demanda menos tempo de conclusão do que o doutorado e Zeppone e Brito (2013) destacam a não continuidade e aprofundamento da temática, que nos parece, aqui, um indicador importante.

Embora em 2008, início do período estudado, temos como marco a Política Nacional de Educação Especial na Perspectiva da Educação Inclusiva (Brasil, 2008), a aprovação e publicação do Decreto $n^{\circ} 6949$ (2009) e ainda, o registro de avanço nas matrículas de pessoas com deficiência no ensino comum, tais dados parece que pouco impulsionaram os estudos acadêmicos voltados para a formação inicial na perspectiva da Educação Inclusiva.

Há que se indicar, também, que anterior ao período da legislação acima mencionada, no que se refere à formação inicial de professores houve a obrigatoriedade da disciplina de Língua Brasileira de Sinais - LIBRAS nos cursos de formação inicial, inserida a partir do Decreto n 5626 (2005). $O$ referido Decreto indica no artigo $3^{\circ}$ que

A Libras deve ser inserida como disciplina curricular obrigatória nos cursos de formação de professores para o exercício do magistério, em nível médio e superior, e nos cursos de Fonoaudiologia, de instituições de ensino, públicas e privadas, do sistema federal de ensino e dos sistemas de ensino dos Estados, do Distrito Federal e dos Municípios (Decreto $n^{\circ} 5626,2005$, p.1).

Com a obrigatoriedade instituída em lei, esta parece ser a formação que vem sendo priorizada aos licenciandos (Oliveira \& Orlando, 2016). Nos demais cursos de Educação Superior, por exemplo bacharelado, a formação em Libras é considerada disciplina curricular optativa (Decreto $n^{\circ} 5626$, 2005).

Atualmente, o Estatuto da Pessoa com Deficiência (2015) aponta a necessidade de ter a disponibilização de programas de capacitação para os profissionais da educação, tanto em serviço quanto em formação. E regulamentando o Estatuto da Pessoa com Deficiência, a Lei n 13.146, (2015) ressalta que é necessário a adoção de práticas pedagógicas inclusivas pelos programas de formação inicial e continuada dos professores. 
Tabela 2. Local de produção.

\begin{tabular}{lll}
\hline Ano & IES/estado & Programa \\
2009 & Universidade Federal de Uberlândia/Minas Gerais & Educação \\
2011 & Universidade Metodista de São Paulo/São Paulo & Educação \\
2011 & Universidade Federal do Paraná/Paraná & Educação \\
2013 & Universidade Presbiteriana Mackenzie de São Paulo/São Paulo & Distúrbio do \\
\hline
\end{tabular}

Fonte: Dados da pesquisa.

Problematizando estes dados, cabe questionarmos: em que local estão se produzindo pesquisas que têm como tema central a formação inicial de professores na perspectiva inclusiva? Quais programas de Pós-Graduação tratam do tema? O que nos dizem os trabalhos?

Do total de quatro trabalhos, foram indicados as IES, os estados e os Programas de Pós-Graduação que se debruçaram sobre a temática.

Ao indicar as Instituições de Ensino Superior (IES) onde os trabalhos foram desenvolvidos, verifica-se uma concentração de três trabalhos em Programas de Pós-graduação em Educação, nos anos de 2009 e 2011, o outro foi realizado em um Programa de Distúrbio do Desenvolvimento. Apesar de diminuto, majoritariamente os trabalhos se concentram na região sudeste do Brasil e em Programas de Pós-Graduação do estado de São Paulo. A saber, no ano de 2009 em Minas Gerais, 2011 e 2013 São Paulo e 2011 Paraná. Não há defesa de mais de um trabalho no mesmo programa ou na mesma instituição.

Tais dados podem nos indicar para além da distribuição e concentração dos locais e Programas de Pós-Graduação, um comprometimento do acúmulo de conhecimentos e a criação e consolidação de linhas de pesquisa (Pastoriza, Orlando, \& Caiado, 2010). Em se tratando do foco deste estudo, a Tabela 3 indica os temas estudados.

Em relação ao tema pesquisado nos trabalhos que se debruçaram sobre a formação inicial de professores na perspectiva inclusiva, três deles se dedicam ao estudo do impacto da política de educação especial na formação inicial de professores, com foco na análise dos conteúdos referentes a Educação Especial presente nas licenciaturas. Um deles, de 2013, se dedica especificamente ao conhecimento adquirido pelos licenciandos, no curso de formação com a disciplina de Libras.

Considerando que, embora a política sinalize a importância da formação inicial dos professores na interface inclusiva, as pesquisas são praticamente escassas. Assim, parece que, apesar do aumento do número de matrículas de pessoas com deficiência no ensino comum (Brasil, 2008) e o paradigma inclusivo, desde a década de 1990 ter ganho força e adentrado os portões escolares, as pesquisas sobre formação inicial de professores para atuar no ensino básico parece ter sido relegada a segundo plano.

No ano 2000, a Proposta de Diretrizes para formação inicial de professores da Educação Básica em cursos de nível superior (Brasil, 2000) reconhece que a educação básica deve ser inclusiva e que a formação dos professores precisa incluir noções relativas ao atendimento dos alunos público-alvo da educação especial.

Tais temáticas, porém, não estão presentes nos cursos de formação de professores, embora devessem fazer parte da formação comum a todos, além de poderem constituir áreas de aprofundamento, caso a instituição formadora avalie que na região isso se justifique. A construção espacial para alunos cegos, a singularidade linguística dos alunos surdos,

Tabela 3.Temática das produções acadêmicas.

\begin{tabular}{lc}
\hline Tema & Quantidade \\
\hline $\begin{array}{l}\text { Conteúdos de Educação Especial no currículo das } \\
\text { licenciaturas }\end{array}$ & 3 \\
& 1 \\
Conhecimentos de licenciandos sobre a disciplina de libras. & 1 \\
\hline
\end{tabular}

Fonte: Dados da Pesquisa. 
as formas de comunicação dos paralisados cerebrais, são outras temáticas a serem refletida. (Brasil, 2000, p. 33).

Em 2015, a Resolução nº 2 (2015) define as Diretrizes Curriculares Nacionais para a formação inicial de nível superior para os cursos de licenciatura, de formação pedagógica para graduandos e de segunda licenciatura, e para formação continuada, e aponta em seu artigo $14 \S 2^{\circ}$, que os

Cursos de formação deverão garantir nos currículos conteúdos específicos da respectiva área de conhecimento ou interdisciplinares, seus fundamentos e metodologias, bem como conteúdos relacionados aos fundamentos da educação, formação na área de políticas públicas e gestão da educação, seus fundamentos e metodologias, direitos humanos, diversidades étnico-racial, de gênero, sexual, religiosa, de faixa geracional, Língua Brasileira de Sinais (Libras), educação especial e direitos educacionais de adolescentes e jovens em cumprimento de medidas socioeducativas. (p.12).

Por outro lado, corroborando com os dados aqui indicados, Oliveira e Orlando (2016) apresentam a análise das grades curriculares dos cursos de licenciatura de uma universidade pública no interior do estado de São Paulo. Os resultados apontam que é quase inexistente o número de disciplinas que tratam da temática educação especial e/ou inclusão escolar nas licenciaturas pesquisadas. Sua invisibilidade só não é completa por conta da presença, na sua maioria, da disciplina Língua Brasileira de Sinais (LIBRAS), conforme indicado, regulamentada pelo Decreto 5626 (2005, p.1), determinou que "a Libras deve ser inserida como disciplina curricular obrigatória nos cursos de formação de professores para o exercício do magistério, em nível médio e superior, e nos cursos de Fonoaudiologia".

Parece que há um impasse que precisa ser pesquisado, primeiro os alunos adentram as escolas, garante-se o acesso, depois pensa-se em sua permanência e apropriação dos conteúdos escolares. Relega-se, talvez, à formação continuada o preparo deste professor para atuar junto aos alunos público alvo da Educação Especial.

Tal dado pode nos sinalizar que, como bem pontuam Pastoriza, Orlando e Caiado (2015), os professores têm aprendido no dia a dia a construir sua prática pedagógica, enfrentando desafios e claro, com todos os comprometimentos de aprendizagem que pode acarretar não só para os alunos com deficiência, como também para o público alvo da Educação Especial. Em relação ao tema destacam que os conteúdos de Educação Especial nos currículos das licenciaturas e o conhecimento sobre a disciplina de Libras recebeu destaque.

De qualquer forma, a análise das produções científicas sob a revisão sistemática aqui apresentada parece apontar para uma mesma direção, qual seja, ainda há muito o que fazer em relação à formação inicial de professores na perspectiva da educação inclusiva. A produção acadêmica, embora em pequeno número, indica que os trabalhos tive- ram uma concentração nos anos de 2009, 2011 e 2013 com um número maior de dissertações de mestrado. Foram desenvolvidos majoritariamente em Programas de Educação e concentrados na região sul/sudeste do Brasil. Quanto ao tema, indicaram conteúdos de Educação Especial no currículo das licenciaturas e os conhecimentos dos licenciandos sobre a disciplina de Libras. Frente a este cenário, pode-se destacar que pela presença de dois marcos importantes na formação inicial de professores na perspectiva inclusiva, quais sejam, em 2008 a Política Nacional da Educação Especial na Perspectiva Inclusiva e em 2015 as Diretrizes Curriculares Nacionais para a formação inicial em nível superior e para a formação continuada, as pesquisas precisam avançar nesta direção.

Como indicamos no início deste artigo, a partir da década de 1990 a sociedade brasileira começou a demonstrar a preocupação com a garantia de direitos sociais e a educação de crianças e jovens público alvo da Educação Especial, fato que tem impactado a formação inicial de professores em uma vertente inclusiva, e nesta direção, os programas de pós-graduação enquanto importantes espaços para a pesquisa científica têm amplo destaque.

Enfim, poderíamos aqui enumerar uma infinidade de importantes e relevantes questionamentos e frentes para outras pesquisas, que acabam envolvendo as recentes e promissoras discussões sobre a formação inicial dos professores e a questão da inclusão escolar de alunos público alvo da Educação Especial no ensino regular, dada a importância de tal temática no presente contexto. E, finalizando, o levantamento de produções aqui apresentado, nas duas bases de dados pesquisadas e no período de 2008 a 2015, aponta para a necessidade de mais pesquisas científicas que se debrucem sobre a presente temática, dada a escassez de trabalhos aprestados. De qualquer forma, acaba por suscitar muitos questionamentos, mas ficam, então, importantes questões: Quais caminhos são possíveis para uma formação inicial de professores na perspectiva da Educação Inclusiva? Que conhecimentos são importantes para esta formação?

\section{Algumas considerações}

Com o objetivo de realizar um levantamento de produções na interface formação inicial e educação inclusiva buscou-se identificar a distribuição das produções de 2008 a 2015, indicar a titulação, identificar as Instituições de Ensino Superior, os Programas de Pós-graduação, bem como as temáticas das pesquisas.

Em número diminuto, no presente trabalho de revisão sistemática foram localizados quatro trabalhos, sendo no ano de 2009, uma tese de doutorado, 2011, duas dissertações de mestrado e 2013, mais uma dissertação de mestrado, todos nas regiões sul/sudeste, especificamente nos estados de São Paulo, Minas Gerais e Paraná. Os Programas de Pós-Graduação em Educação parecem ser os mais envolvidos nas pesquisas sobre a formação inicial na perspectiva inclusiva. 
Os dados aqui apresentados apontam que os Programas de Pós-Graduação têm se debruçado sobre a análise dos conteúdos curriculares das licenciaturas e o conhecimento dos alunos no que diz respeito à disciplina de Libras. Nesse cenário pode-se inferir que a política começa a indicar novas diretrizes para a formação inicial dos professores, coloca questões pontuais e nevrálgica desta formação. Chega-se o momento de transcender questões sobre o acesso e a apropriação dos conteúdos escolares dos sujeitos público alvo da Educação Especial, já que os professores da Educação Básica aprendem a construir sua prática pedagógica com as dificuldades apresentadas no seu dia a dia da docência, acarretando comprometimentos na aprendizagem dos alunos.

Almeja-se que os dados aqui apresentados contribuam com a comunidade acadêmica e científica no sentido de avançar não só com as pesquisas, mas também na formação inicial de professores na perspectiva inclusiva. Entretanto, pouco se tem pesquisado sobre a temática e praticamente são escassos trabalhos que indiquem conteúdos, referenciais teóricos ou metodológicos, presentes nesta formação para lidar com estes sujeitos.

Talvez este seja o indicativo da necessidade dos Programas de Pós-Graduação brasileiros se atentarem para a interface aqui proposta e quem sabe, para a construção de um diálogo mais profundo entre a formação inicial de professores e a prática pedagógica na perspectiva da Educação Inclusiva, na tentativa de no estágio inicial de formação os professores se apropriarem de conhecimentos sobre intervenções efetivas com o público alvo da Educação Especial.

\section{Referências}

Bem, A. (2006). Centralidade dos movimentos sociais na articulação entre o Estado e a sociedade brasileira nos séculos XIX e XX. Revista Educação e Sociedade, 27 (97).

Brasil (1988). Constituição da República Federativa do Brasil. Brasília: Diário Oficial da República Federativa da União. Recuperado: 30 de jun. 2016. Disponível: http://www.planalto.gov.br/ccivil_03/ Constituicao/Constituicao.htm.

Brasil. Ministério da Educação (2000). Proposta de Diretrizes para a formação inicial de professores da educação básica, em cursos de nível superior. Recuperado: 28 jun. 2016Brasília: MEC. Disponível: http://portal.mec.gov.br/cne/arquivos/pdf/basica.pdf

Brasil. Ministério da Educação (2008). Política Nacional de Educação Especial na perspectiva da Educação Inclusiva. Brasília: MEC/ SEESP.Recuperado: 30 jun. 2016. Disponível: http://portal.mec. gov.br/arquivos/pdf/politicaeducespecial.pdf

Bueno, J.G.S. (2010). Deficiência e ensino superior: balanço das dissertações e tese brasileiras (1987/2005). In: Victor, S. L.; Drago, R.; Chicon, J. F. (Orgs.), A educação inclusiva de jovens e adultos: avanços e desafios (pp. 255-272). Vitória: EDUFES, 2010.
Costa, A.B; Zaltowski, A.P.C. (2014). Como escrever um artigo de revisão sistemática. In: Koller, C. H.; Couto, C.P. P.; Hohendorff, J. V. (Orgs), Manual de Produção Científica. (pp. 55-70). Porto Alegre: Penso.

Decreto $n^{\circ}$ 5626, de 22 de dezembro de 2005 (2005, 22 de dezembro). Regulamenta a Lei no 10.436, de 24 de abril de 2002, que dispõe sobre a Língua Brasileira de Sinais - Libras, e o art. 18 da Lei no 10.098, de 19 de dezembro de 2000. Brasília, DF: Diário Oficial da República Federativa do Brasil. Recuperado: 30 jun. 2016. Disponível: http://www.planalto.gov.br/ccivil_03/_ato20042006/2005/decreto/d5626.htm

Decreto $n^{\circ}$ 6.949, de 25 de agosto de 2009 (2009, 25 de agosto). Promulga a Convenção Internacional sobre os Direitos das Pessoas com Deficiência e seu Protocolo. Brasília, DF: Diário Oficial da República Federativa do Brasil. Recuperado: 29 jun. 2016. Disponível: http://www.planalto.gov.br/ccivil_03/_ato20072010/2009/decreto/d6949.htm

Gatti, B.A. (2004). Estudos quantitativos em educação. Revista Educação e Pesquisa, 30 (1), 11-30.

Gohn, M.G. (1995). História dos movimentos e lutas sociais: a construção da cidadania dos brasileiros. São Paulo: Loyola.

Hohendorff, J.V. (2014). Como escrever um artigo de revisão de literatura. In: Koller, C. H.; Couto, C.P. P.; Hohendorff, J. V. (Orgs), Manual de Produção Científica(pp. 39-54). Porto Alegre: Penso.

Lei $n^{\circ}$ 12.796, de 4 de abril de 2013 (2013, 4 de abril). Altera a Lei 9394 de 1996 que estabelece as diretrizes e bases da educação nacional, para dispor sobre a formação dos profissionais da educação e dar outras providências. Brasília, DF: Diário Oficial da República Federativa do Brasil. Recuperado: 29 jun. 2016. Disponível: http://www.planalto.gov.br/ccivil_03/_ato20112014/2013/lei/l12796.htm

Lei $n^{\circ}$. 13.146, de 6 de julho de 2015 (2015, 6 de julho). Institui a Lei Brasileira da Pessoa com Deficiência (Estatuto da Pessoa com deficiência). Brasília, DF: Diário Oficial da República Federativa do Brasil. Recuperado: 30 jun. 2016. Disponível: http://www.planalto. gov.br/ccivil_03/_Ato2015-2018/2015/Lei/L13146.htm

Leone, N.M.; Leite, Y.U.F. (2011). O Início da Carreira Docente: implicações à formação inicial de professores. Revista Eletrônica Pesquiseduca, 3 (6), 236- 259.

Mello, G.N. (2000) Formação Inicial de Professores para a Educação Básica: uma (re)visão radical. Revista São Paulo Perspectiva, 14 (1), 98-110.

Oliveira, L.P.; Orlando, R.M. (2016). Matrizes curriculares de licenciaturas da UFSCar: Um olhar voltado para a inclusão escolar? In: Poker, R.B.; Martins, S.E.S.O.; Giroto, C.R.M. (Orgs.), Educação inclusiva: em foco a formação de professores. (pp. 7794), São Paulo: Cultura acadêmica. 
Organização das Nações Unidas [ONU] (1948). Declaração universal dos direitos humanos. Adotada e proclamada pela resolução 217 A (III) da Assembleia Geral das Nações Unidas. Geneva: ONU. Recuperado: 28 jun. 2016. Disponível: www.direitoshumanos.usp. br.

Orlando, R.M.; Caiado, K.R.M. (2014). Professores universitários com deficiência: trajetória escolar e conquista profissional. Educação \& Realidade, 39 (3), 811-830.

Pastoriza, T. B.; Orlando, R.M.; Caiado, K.R. (2015). Produção do conhecimento sobre ensino de geografia para pessoas com deficiência. Revista Ibero-Americana de Estudos em Educação, 10 (especial), 773-786.

Resolução n², de 1 de julho de 2015. Define as Diretrizes Curriculares Nacionais para a formação inicial em nível superior (cursos de licenciatura, cursos de formação pedagógica para graduados e cursos de segunda licenciatura) e para a formação continuada. Brasília, DF: Diário Oficial da República Federativa do Brasil. Recuperado: 30jun. 2016. Disponível: http://pronacampo.mec.gov. br/images/pdf/res_cne_cp_02_03072015.pdf
Saviani, D. (2005). Escola e democracia (37 ed). Campinas: Autores Associados.

Silva, R. H. R.; Gamboa, S. S. (2011). Análise Epistemológica da Pesquisa em Educação Especial: A Construção de um Instrumental de Análise. Revista Atos De Pesquisa Em Educação, 6 (2), 373-402

UNESCO (1994). Declaração de Salamanca sobre Princípios, Políticas e Práticas na Área das Necessidades Educativas Especiais. In: Conferência Mundial sobre Necessidades Educativas: Acesso e Qualidade. Salamanca, Espanha: Unesco.

Zeppone, R.M.O.; Brito, J. (2013). Ensino superior e pessoas com deficiência: mapeamento de teses e dissertações. In: Caiado, K.R.M. (Org), Trajetórias escolares de alunos com deficiência (pp. 93-114). São Carlos, SP: EDUFSCar.

License information: This is an open-access article distributed under the terms of the Creative Commons Attribution License (type CCBY), which permits unrestricted use,distribution and reproduction in any medium, provided the original article is properly cited.

\section{Sobre as autoras}

Patrícia Aparecida Monico (pati_monico@hotmail.com)

Acadêmica de Licenciatura em Educação Especial pela Universidade Federal de São Carlos (2014-2017). É pesquisadora no Grupo GEPEPI também na Universidade Federal de São Carlos. São Carlos - SP.

https://orcid.org/0000-0003-1872-1693

Liz Amaral Saraiva Morgado (saraiva_liz@hotmail.com)

Graduada em Licenciatura em Educação Especial pela Universidade Federal de São Carlos (2013). Mestranda pelo Programa de Pós Graduação em Educação Especial - UFSCar, bolsista CNPq. São Carlos - SP.

https://orcid.org/0000-0002-2872-9931

Rosimeire Maria Orlando (meiremorlando@gmail.com)

Graduada em Licenciatura Plena em Pedagogia, com habilitação em Educação Especial: Ensino Deficientes Mentais, pela Universidade Estadual Paulista Júlio de Mesquita Filho (1991). Mestre em Metodologia do Ensino pela Universidade Federal de São Carlos (1996), Doutorado em Educação Escolar pela Universidade Estadual Paulista Júlio de Mesquita Filho (2005) e Pós-doutorado pela Universidade Federal de São Carlos - Departamento de Psicologia. Professora adjunta na Universidade Federal de São Carlos, licenciatura em Educação Especial e no Programa de Pós-Graduação em Educação Especial/UFSCar. São Carlos - SP.

https://orcid.org/0000-0002-0990-6146 